The Journal of Laryngology \& Otology

http://journals.cambridge.org/JLO

Additional services for The Journal of Laryngology \& Otology:

Email alerts: $\underline{\text { Click here }}$

Subscriptions: $\underline{\text { Click here }}$

Commercial reprints: $\underline{\text { Click here }}$

Terms of use : $\underline{\text { Click here }}$

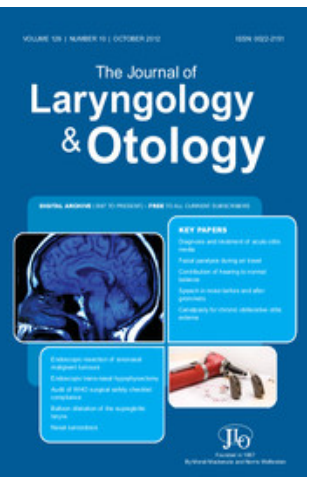

\title{
Current practice in the management of frontal sinus fractures
}

B.D. Swinson, W. Jerjes and G. Thompson

The Journal of Laryngology \& Otology / Volume 118 / Issue 12 / December 2004, pp 927 - 932

DOI: 10.1258/0022215042790583, Published online: 08 March 2006

Link to this article: http://journals.cambridge.org/abstract_S0022215104002440

How to cite this article:

B.D. Swinson, W. Jerjes and G. Thompson (2004). Current practice in the management of frontal sinus fractures. The Journal of Laryngology \& Otology, 118, pp 927-932 doi:10.1258/0022215042790583

Request Permissions : $\underline{\text { Click here }}$ 


\title{
Current practice in the management of frontal sinus fractures
}

\author{
B. D. Swinson, A.F.R.C.S., F.D.S.R.C.S., W. JeRJes, B.D.S., M.SC., G. ThOMPSON, M.B.B.CH., M.R.C.P.
}

\begin{abstract}
Fractures of the frontal sinus are seen predominantly, although not exclusively, in young men and are usually the result of road traffic accidents or falls.

These types of injury may present to either ENT, Maxillofacial, Plastic or Neurosurgery teams, and understanding of a clear management protocol is desirable for each of the specialties. The optimal management of these injuries is becoming more uniformly adopted although some areas of contention still persist. The aim of treatment has always been directed at creating a 'safe sinus' that is not complicated by the late sequelae of infection or mucocele formation. The difficulty lies in being able to predict which patients are likely to develop these complications.

The aim of this paper is to evaluate the literature and offer a rationale for the management of these injuries.
\end{abstract}

Keywords: Frontal Sinus; Fractures; Surgical Procedures, Operative; Treatment Outcome

\section{Incidence and aetiology}

Fractures of the frontal sinus are a relatively common injury presenting to trauma units which deal with cranio-facial injuries.

Approximately one-third of frontal sinus fractures affect the anterior wall alone, with two-thirds involving the anterior wall, posterior wall or frontonasal duct. Isolated posterior wall defects are exceedingly rare.

The incidence has been estimated between 6 per cent and 12 per cent of all such injuries. ${ }^{1,2}$ Fractures involving both the anterior and posterior walls have been claimed to involve 0.7 per cent to 2.1 per cent of craniocerebral trauma. ${ }^{3}$ The aetiology of these injuries is usually the result of high velocity impacts, road traffic accidents being the main mechanism followed by falls. ${ }^{4}$ These high velocity impacts are usually associated with polytrauma and in this setting it is easy to understand the finding that these injuries are often overlooked. Wallis and Donald found that 75 per cent had other associated injuries, 52 per cent of patients presented in shock and 42 per cent were comatose on admission. ${ }^{5}$

The complications of delayed or improper treatment may incur considerable morbidity.

\section{Embryology and anatomy of the frontal sinus}

The frontal sinuses are absent at birth but start to develop during the second year of life from several outgrowths originating from the frontal recess, giving rise to the nasofrontal duct $;^{6}$ clinically relevant sinuses only appear in late childhood. Eighty-five percent of the population have a foramina rather than a true duct. ${ }^{7}$ Only in the patient whose nasofrontal duct opens directly into the frontal recess or above the infundibulum ( 85 per cent of cases) is the frontal sinus accessible to intranasal cannulation.

Both frontal sinuses are roughly triangular in shape, although rarely symmetrical. The average measurements are $28 \mathrm{~mm}$ in height, $27 \mathrm{~mm}$ in width and $17 \mathrm{~mm}$ in depth, ${ }^{8}$ with an entire surface area of approximately $720 \mathrm{~mm}^{2,9}$ Failure to develop is seen in 4 per cent of the population.

The sinuses drain into the middle meatus of the nasal cavity by way of the ethmoid labyrinth in 50 per cent of cases. ${ }^{6}$ The venous drainage is through the angular and anterior facial veins, with a small element through the foramen of Breschet in the posterior wall, which drains into the subdural venous system. It is this central communication that assists the spread of organisms should infection supervene. ${ }^{10}$

\section{Clinical diagnosis}

The clinical diagnosis of a frontal sinus fracture may be difficult to establish due to the presence of overlying soft tissue oedema. A high index of suspicion is therefore needed with this pattern of injury. Careful examination of the surrounding nasoethmoidal area should be carried out to rule out concomitant injury.

Clinical signs are usually depression of the area of the frontal sinus or bony fragments protruding 


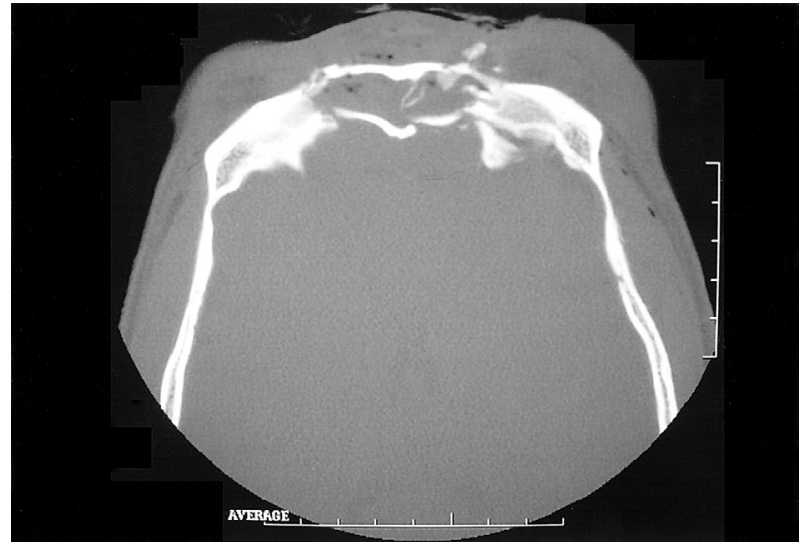

FIG. 1

Axial CT with combined anterior and posterior wall fractures.

through lacerations. Anaesthesia or paraesthesia of the supraorbital nerves, subconjunctival ecchymosis, CSF rhinorrhoea or air within the orbital cavity may also raise suspicion of this pattern of injury. ${ }^{11}$ Patients presenting with rhinorrhoea or a suspected CSF leak should raise the suspicion of disruption of the posterior wall with a dural tear, although it should be noted that a dural tear may present without CSF rhinorrhoea if the outflow is blocked. ${ }^{12}$ Clinically, CSF presents as a clear or slightly yellow discharge, although if mixed with blood produces an appearance likened to 'tramlines' due to the higher protein content of the CSF. This is also the basis of the 'halo' test ${ }^{13}$ carried out on absorbent cloth. Biochemical analysis of the fluid revealing beta-2transferrin confirms the diagnosis.

Thorough neurological and ophthalmic examination is mandatory in all traumatic injuries of the frontal area.

\section{Imaging}

While Caldwell ${ }^{14}$ and Waters' projections provide good views of the vertical height of the frontal sinus, ${ }^{6}$ and lateral skull views display the anterior and posterior tables well, spiral computerized tomography is currently the gold standard for

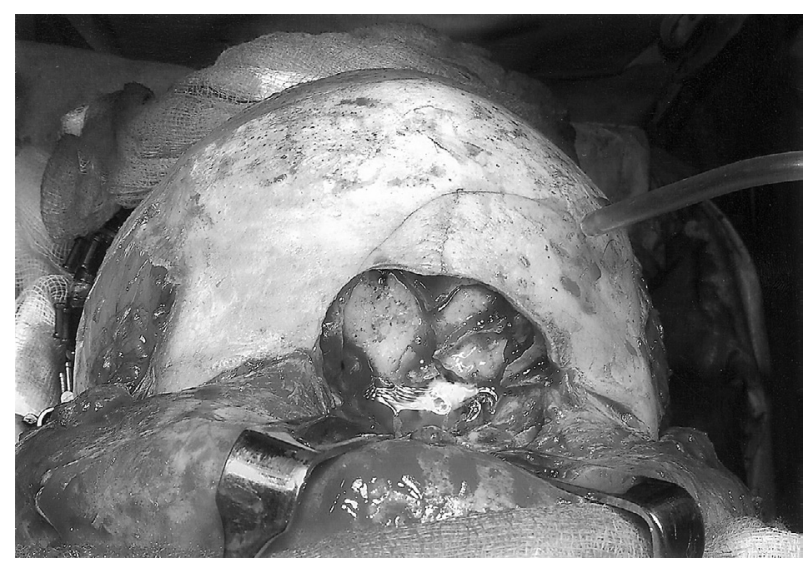

FIG. 2

Depressed comminuted fracture of the anterior wall.

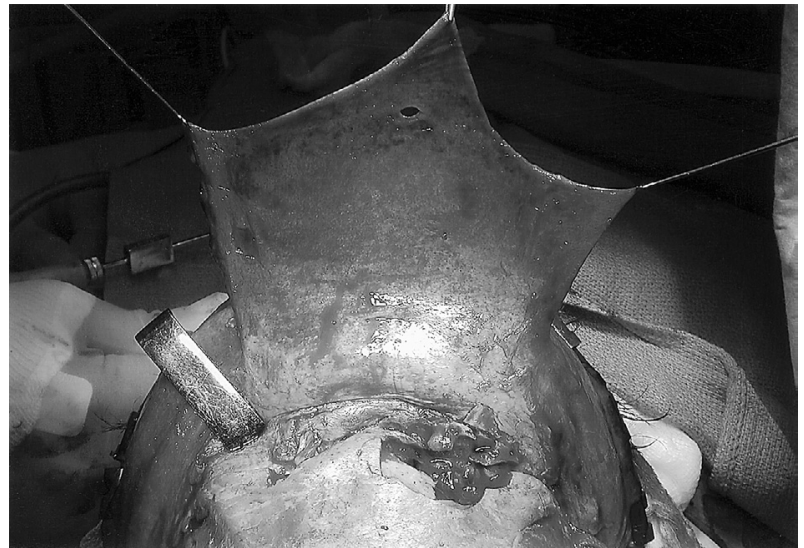

FIG. 3

Raising of the pericranial flap to be used for cranialization of the sinus in complex defects.

evaluating the paranasal sinuses. ${ }^{15}$ Assessment of both skeletal and soft tissue elements can be achieved, with high spatial resolution, using the respective windows and with contrast enhancement can help differentiate fluid from solid tissue thickening within the sinus. The coronal views are superior for the sinus floor and roof, while axial views demonstrate the anterior and posterior walls (Figure 1). ${ }^{16}$ Three-dimensional reconstruction can prove invaluable if custom-made implants are required to repair the defect in the event of tissue loss.

\section{Classification}

Throughout the literature several classifications of frontal sinus fractures have been proposed $^{1,5,11,12,17-19}$ comparing clinical fracture patterns, degree of displacement and CT findings.

The most recent classification by Gonty et $a l^{20}$ separated the fracture patterns into four groups:

(1) Type I, anterior wall fractures.

(2) Type II, anterior wall posterior table fractures.

(3) Type III, posterior wall fractures.

(4) Type IV, through-and-through fractures of the sinus.

The choice of which classification to use is a personal preference, although all are descriptive of

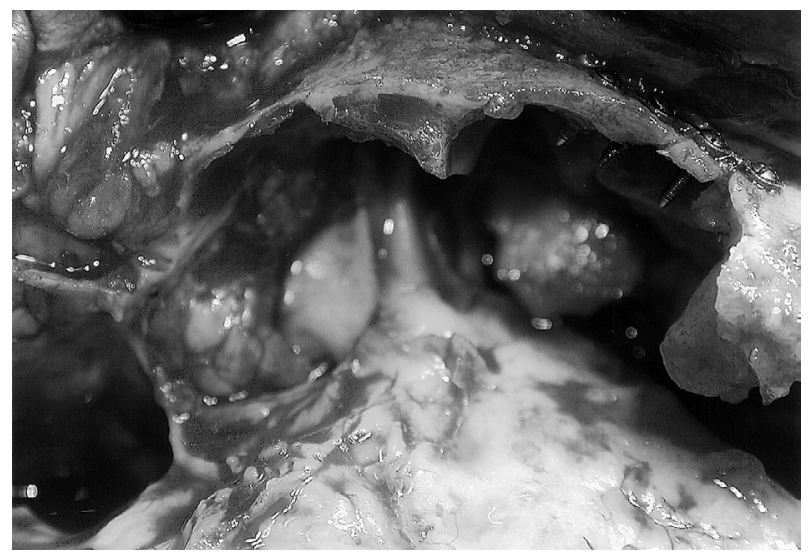

FIG. 4

Frontal sinus floor exposed to assess disruption of the floor and patency of the duct. 


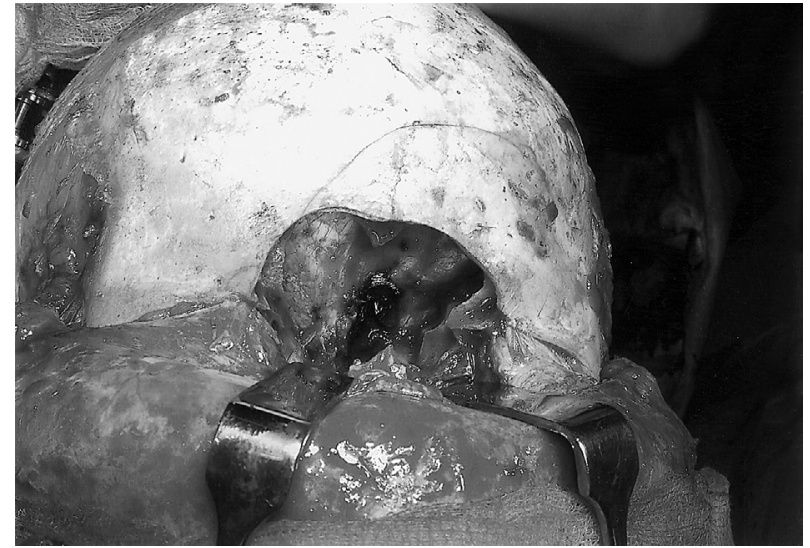

FIG. 5

Posterior wall defect with exposed dura visible.

fracture patterns but offer no guidelines as to the appropriate management.

\section{Treatment principles}

The main treatment questions to be answered are:

(1) Is this an isolated anterior wall fracture?

(2) Is the posterior wall involved?

(3) Is there evidence of disruption of the nasofrontal duct?

(4) What is the degree of displacement?

When setting out to formulate a treatment plan for the management of this type of injury the main objective is to provide a 'safe' sinus which protects the brain from either short or long term infective sequelae. Cosmesis and sinus function should also be considered at this stage.

While management of anterior wall fractures is well standardized, the optimal treatment of posterior wall fractures involving the naso-frontal duct is still debated.

Disruption of the posterior wall integrity may guide the surgeon to provide a barrier to isolate the intracranial contents from the nasal cavity. In the absence of a CSF leak, many minor fractures of the posterior wall can be managed by repairing the defect without requiring 'cranialization'. If the mucosa can largely be preserved, the nasofrontal recess opened widely and the bony walls restored, this may prove sufficient.

With the presence of a persistent CSF leak, cranialization of the defect is now being increasingly undertaken.

Disruption of the sinus floor and naso-frontal duct with an intact posterior wall is usually managed by sinus obliteration.

\section{Anterior wall fractures}

Isolated, closed fractures involving an undisplaced anterior wall only do not require operative treatment and can be managed conservatively with nasal decongestants. Minimally displaced anterior wall fractures can also be treated in this fashion if the cosmetic defect does not pose a problem.

It is advisable to explore all open fractures to assess the true extent of the injury, the patency of the nasofrontal duct, and to plan the management accordingly.

Isolated depressed fractures with no involvement of the duct require reduction of the bony fragments and micro-plate fixation to restore the cosmetic defect. The repair is best performed via a coronal approach, which offers excellent access with good cosmetic results (Figure 2). A concomitant overlying laceration may be used on occasion but this offers inferior access.

The dissection proceeds in a supra-periosteal plane, with preservation of the pericranium. This should remain pedicled at its caudal end to be used as a pericranial flap if cranialization is later found necessary (Figure 3). The fragments are reduced and secured, preferably using micro-plates.

With severely comminuted fractures, the bone may have to be debrided prior to replacement and fixation and should be temporarily stored in saline or blood-soaked gauze swabs. Any significant loss of bony contour can have a profound cosmetic effect and it is advisable to replace any defect larger than $1.5 \mathrm{~cm} .{ }^{21}$ Calvarial outer table, rib or the iliac crest provide excellent graft sources.

\section{Fractures involving the frontal sinus floor}

Isolated fractures of the floor of the frontal sinus are very rare and are usually associated with fractures of the naso-ethmoidal complex. These injuries, in turn, are more likely to involve disruption of the nasofrontal duct (Figure 4). It is this blockage or disruption of the nasofrontal duct that affects the normal mucociliary drainage and predisposes to infective complications, such as sinusitis, mucocele, pyocele or osteomyelitis.

Historically, several methods have been proposed for the management of damage to the nasofrontal duct. MacBeth ${ }^{22}$ simply removed all the mucosa and did not obliterate the cavity, and as long as the duct was occluded claimed good results, although this technique has been questioned by subsequent authors.

Luce $^{23}$ proposed placing an indwelling catheter through the damaged duct into the nose for two weeks, while Onishi et al. ${ }^{24}$ passed a silicone tube after first enlarging the opening to the duct to 5-8 $\mathrm{mm}$. The long-term results of attempted duct restoration have been poor due to the propensity for mucosal proliferation with subsequent scar formation and stenosis. Failure rates of 30 per cent have been shown. ${ }^{25}$ The use of larger stents induces pressure necrosis and marked fibrosis of the duct. In the last decade there has been an increasing trend to mucosal preservation of the duct. It is now possible to open the duct widely by sub-mucosal dissection to remove agger nasi and bullae frontalis cells to expand the duct diameter while maintaining the mucosal integrity, and results have been encouraging.

Most authors now propose that the treatment of duct disruption with an intact posterior wall should be sinus obliteration.

The principle of this management is to remove all the sinus mucosa by careful dissection, while 


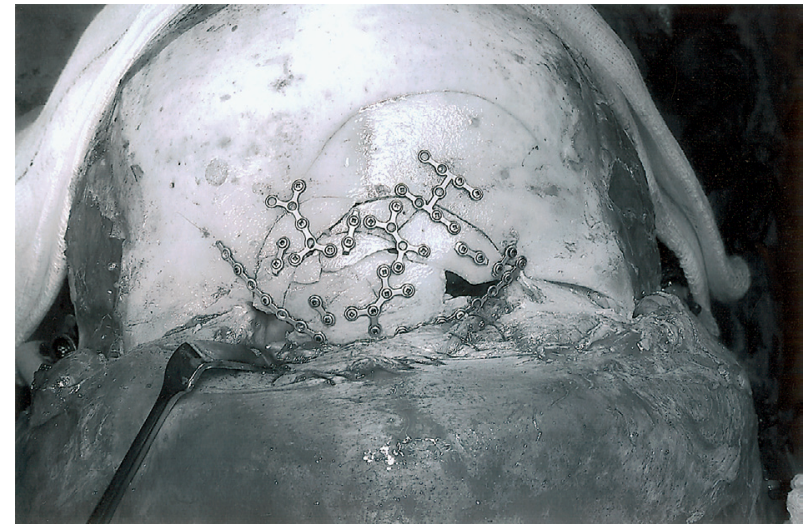

FIG. 6

Reconstitution of the anterior wall fragments using mini-plate fixation.

removing the small invaginations present in the foramina of Breschet, usually with a burr. The nasofrontal duct is then packed with material, usually fascia or a pedicled pericranial flap being rotated into the sinus to separate it from the nasal cavity. This is then followed by total obliteration of the dead space with a choice of materials. The anterior wall fragments are then reduced and fixed, followed by closure of the coronal flap.

\section{Posterior wall fractures}

Disruption of the posterior wall has been shown to complicate 80 per cent of fractures involving the frontal sinus. ${ }^{5}$ This injury, with or without a demonstrable CSF leak, is associated with a high incidence of dural tear. The presence of pneumocephalus or displacement of fracture by more than the thickness of the posterior wall should raise the suspicion of a dural tear. In these instances there is a high risk of long-term infective complications and surgical exploration is warranted. The surgical objective with this pattern of sinus injury is to restore dural integrity and to isolate the cranial cavity from potential communication of pathogens from the nose.

Again, access is usually via a coronal approach with preservation of a pedicled pericranial flap that is required later. Anterior wall fragments are removed and stored as previously stated and the posterior wall examined (Figure 5). If the posterior table is severely comminuted it is probably wise to cranialize the frontal sinuses rather than obliterate them. Prior to dural repair, the posterior wall fragments should be removed with bone nibblers or an acrylic burr. This effectively cranializes the frontal sinus and improves the access to the anterior fossa.

Small tears can be sealed with absorbable sutures or fibrin glue, while larger defects may require a patch graft of fascia lata or pericranium.

The sinus lining is meticulously removed and the floor and inner cortex abraded with a burr. The duct is obliterated, usually with fascia or a pericranial flap to separate the anterior fossa from the nasal cavity. Restoration of the anterior wall is then achieved by replacing the fragments and immobilizing with minior micro-plates (Figure 6).

\section{Obliteration materials}

The first evidence of obliteration of the sinus was described by Reidel in $1898^{26}$ using the overlying skin as the ablative material, with obvious aesthetic problems. During the early twentieth century modifications of the Lynch procedure ${ }^{27}$ predominated. Later several attempts at providing a surrogate duct were undertaken. These included gold tubes, rubber hoses and Tantalum foil. ${ }^{28}$

The poor success rate of these procedures stimulated the rise of osteoplastic techniques.

The technique of obliteration with osteoneogenesis was first described by MacBeth ${ }^{22}$ in 1954, who occluded the duct but not the cavity. Attention then turned to exogenous materials in animal models. Gelfoam, Ivalon sponges, blood clot, Teflon paste, melted paraffin and silastic sponge have all been tried with varying degrees of success. ${ }^{29}$

Lyophilized cartilage $^{30}$ has shown good results, although it has now fallen out of favour due to the risk of viral transmission, and hydroxyapatite ${ }^{31}$ and Ionomer cement ${ }^{32}$ have now superseded polymethylmethacrylate as the alloplastic material of choice.

Autogenous fat ${ }^{33,34}$ and muscle $e^{3,35}$ have been used, although $\mathrm{McNeil}^{36}$ showed that while muscle was as effective as fat in obliteration, the fat remained viable while the muscle was replaced by fibrous tissue.

Cancellous bone $e^{28,37,38}$ is probably now the most widely used substance and is felt to be the material of choice for sinus obliteration. ${ }^{39}$

Ultimately, the choice of material is a matter of personal preference, but thorough removal of the sinus lining and meticulous packing of the material, in the duct orifice and the cavity to be obliterated, is the key to success.

\section{Early and late complications}

Rohrich and Hollier ${ }^{13}$ described frontal sinus complications as 'early' if occurring within six months of injury and 'late' if occurring after that period.

Early problems include wound infection, CSF leak, seroma or haematoma under the coronal flap, frontal sinusitis, headache, meningitis, encephalitis and brain abscess. Meningitis has been estimated as a complication of frontal sinus fracture in 6 per cent of cases. ${ }^{5}$ Of the minor complications, frontal headache is the most commonly described, with contour deformity and supraorbital nerve paraesthesia also cited.

Late complications can occur up to several years post-injury, which necessitates long-term, regular follow up. Clinical and computed tomography follow up have been advocated for 10 years post-injury in 'through and through' injuries. ${ }^{40}$

Failure to eradicate any persistent infection may lead to late sinusitis. Mucocele formation occurs due to areas of mucosa which become separated from the rest of the sinus and thus cannot drain, and has been estimated at 10 per cent of cases. Infection can cause mucopyocele formation and may lead to epidural or subdural abscesses, with potentially devastating consequences. Late meningitis and encephalitis are also well recognized. 
It is important to stress that the benefits of any active intervention must be balanced against the risk of the development of epilepsy post-craniotomy.

Due to the possibility of late infective sequelae, regular follow up of these patients is advised.

\section{The future}

Several units are now using biocompatible resorbable plates with good effect, while others are utilizing an endoscopic approach to treat anterior wall fractures and to avoid the morbidity of the coronal approach.

\section{Conclusion}

The once controversial management of this pattern of injury has, over a period of time, become more standardized. The main rationale in the treatment of these craniofacial injuries is to prevent late infective sequelae and if possible establish drainage of the whole frontal sinus.

Anterior wall fractures should be treated on a cosmetic basis; treatment of displaced posterior wall fractures aims to isolate the nasal from the cranial cavities sinus, with obliteration or cranialization of the sinus with a vascularized pericranial flap. Attempts to re-establish the nasofrontal duct with stents should be avoided, but if used they should be loose-fitting.

- The surgical management of fractures involving the frontal sinuses may be complicated by the late sequelae of infection or mucocele formation

- This paper evaluates the literature and offers a rationale for the management of these injuries

Obliteration has a role to play when it is not possible to reconstruct the walls, and it is unlikely that drainage of the whole frontal sinus will be achieved.

Cranialization has a role where the posterior wall is severely damaged and cannot be reconstructed, but it is important to remove all of the mucosa from the sinus and to obliterate the duct to ensure success.

\section{References}

1 Luce EA. Frontal sinus fractures: guidelines to management. Plast Reconstr Surg 1987;80:500-8

2 Ioannides C, Freihoffer HP, Friens J. Fractures of the frontal sinus: a rationale for treatment. Br J Plast Surg 1993:46:208-14

3 Sataloff RT, Sariego J, Myers DL, Richter HJ. Surgical management of the frontal sinus. Neurosurgery 1984; 15:593-6

4 Vasconez HC, Luce EH. Frontoethmoidal fractures. In: Habal MB, Ariyan S. Facial Fractures. Philadelphia: BC Decker, 1989:105-16

5 Wallis A, Donald PJ. Frontal sinus fractures: A review of 72 cases. Laryngoscope 1988;98:593-8

6 Som PM, Brandwein M. Sinonasal cavities: anatomy, physiology and plain film normal anatomy. In: Som PM, Curtin HD. Head and Neck Imaging. St Louis: Mosby, 1996:61-96
7 Montgomery WM. Surgery of the Upper Respiratory System. Philadelphia: Lea and Fabiger, 1971

8 Schaefer JP. The Nose, Paranasal Sinuses, Nasolacrimal Passageways and Olfactory Organs in Man. Philadelphia: Blakistons, 1920

9 Haug RH, Likavec MJ. Basics of stable internal fixation in cranial surgery. In: Greenberg A. Craniomaxillofacial Fractures: Principles of Internal Fixation Using the AO/ASIF Technique. New York: Springer-Verlag, 1993: 179-83

10 Helmy ES, Koh RA, Bays RA. Management of frontal sinus fractures. Review of the literature and clinical update. Oral Surg Oral Med Oral Pathol 1990;69:137-48

11 Adkins WY, Cassone RD, Putney FJ. Solitary frontal sinus fracture. Laryngoscope 1979;89:1099-104

12 Newman MH, Travis NL. Frontal sinus fracture. Laryngoscope 1973;83:1281-92

13 Rohrich RJ, Hollier LH. Management of frontal sinus fractures. Clin Plast Surg 1992;19:219-32

14 Caldwell EW. Skiagraphy of the accessory sinuses of the nose. Am J Roentgenol 1918;5:569

15 Zinreich S. Paranasal sinus imaging. Otolaryngol Head Neck Surg 1990;103:863-8

16 Heller EM, Jacobs JB, Holliday RA. Evaluation of the frontonasal duct in frontal sinus fractures. Head Neck 1989;11: 4-50

17 Rowe NL, Killey HC. Fractures of the nasal region, frontal sinus and paranasal air-sinuses. In: Rowe NL, Killey HC. Fractures of the Facial Skeleton. Edinburgh: Livingstone, 1968:263-75

18 Donald PJ, Bernstein L. Compound frontal sinus injuries with intracranial penetration. Laryngoscope 1978;88:225-32

19 Stanley RB. Fractures of the frontal sinus. Clin Plast Surg 1989;16:115-23

20 Gonty AA, Marciani RD, Adornato DC. Management of frontal sinus fractures: a review of 33 cases. J Oral Maxillofac Surg 1999;57:372-9

21 Gonty AA. Management of frontal sinus fractures and associated injuries. In: Fonseca RJ. Oral and Maxillofacial Surgery, Vol 3. Philadelphia: WB Saunders, 2000:308-11

22 MacBeth R. The osteoplastic operation for chronic infection of the frontal sinus. J Laryngol Otol 1954; 68:465-77

23 Luce EA. Frontal sinus fractures: guidelines to management. Plast Reconstr Surg 1987;80:500-8

24 Onishi K, Nakajima T, Yoshimura Y. Treatment and therapeutic devices in the management of frontal sinus fractures. J Craniomaxillofac Surg 1989;17:58-63

25 Wilson BC, Davidson B, Corey JP, Haydon RC. Comparison of complications following frontal sinus fractures managed with exploration with or without obliteration over 10 years. Laryngoscope 1988;98:516-20

26 Reidel K. Schenke Inaugural Dissertation. Jena, 1898

27 Lynch RC. The technique of a radical frontal sinus operation which has given me the best results. Laryngoscope 1921;31:1-5

28 Goodale RL. The rationale of frontal sinus surgery. Laryngoscope 1965;75:981-7

29 Sessions RB, Alford BR, Stratton JZ, Ainsworth JZ, Shill O. Current concepts of frontal sinus surgery: An appraisal of the osteoplastic flap-fat obliteration operation. Laryngoscope 1972;82:918-30

30 Sailer HF, Gratz KW, Kalavresos ND. Frontal sinus fractures: principles of treatment and long term results after sinus obliteration with the use of lyophilized cartilage. J Craniomaxillofac Surg 1998;26:235-42

31 Rosen C, Nachtigal D. The use of hydroxyapatite for obliteration of the human frontal sinus. Laryngoscope 1995;105:553-5

32 Weber A, May A, von Ilberg C. Bone replacment by ionomer cement in osteoplastic frontal sinus operations. Eur Arch Otorhinolaryngol 1997;254:162-4

33 Hardy JM, Montgomery WW. Osteoplastic frontal sinusotomy: An analysis of 250 operations. Ann Otol Rhinol Laryngol 1976;85:523-32

34 Bergara AR, Itoiz A. Present state of the surgical treatment of chronic frontal sinusitis. Arch Otolaryngol 1955;61:616-28 
35 Mason PN, Crawley JE, Hoopes JE. Frontal cranioplasty: Risk factors and choice of cranial vault reconstruction material. Plast Reconstr Surg 1986;77:888-904

36 McNeil RA. Surgical obliteration of the maxillary sinus: A clinical and experimental study. Laryngoscope 1967;77:202-17

37 Scumrick KA, Smith CP. The use of cancellous bone for frontal sinus obliteration and reconstruction of frontal bony defects. Arch Otolaryngol Head Neck Surg 1994;120:1003-9

38 Hybels RL. Posterior table fractures of the frontal sinus. II. Clinical aspects. Laryngoscope 1972;87:1740-5

39 Owens M, Klotch DW. Use of bone for obliteration of the nasofrontal duct with the osteoplastic flap: a cat model. Laryngoscope 1993;103:883-9

40 Smoot EC, Bowen DG, Lappert P, et al. Delayed development of an ectopic frontal sinus mucocele after paediatric cranial trauma. J Craniofac Surg 1995;4:327-31
Address for correspondence:

Mr B.D. Swinson,

Dept of Maxillofacial Surgery,

UCL Hospital,

Mortimer Market,

London WC1E 6AU, UK.

Fax: 02073809855

E-mail: brianswinson@totalise.co.uk

Mr B.D. Swinson takes responsibility for the integrity of the content of the paper.

Competing interests: None declared 